\title{
Twenty-five years of excellence: a retrospective glance of Acta Mechanica Sinica
}

\author{
Geng-Dong Cheng
}

Published online: 17 December 2010

(C) The Chinese Society of Theoretical and Applied Mechanics and Springer-Verlag GmbH 2010

The first version of Acta Mechanica Sinica (AMS) was launched in June 1985 in Beijing, aimed at delivering the cutting-on-edge progress and achievement in Mechanics in China to the world, allowing world-round colleagues to access the work of Chinese mechanician, and supplying an international forum in the field. Its appearance was a result of 5-year preparation after the consensus agreement by the Acta Mechanica Sinica Editorial Board (3rd), and was approved by the China Association for Science and Technology and supported by the Chinese Society of Theoretical and Applied Mechanics (CSTAM).

\section{High quality}

At the initial stage, papers published in AMS selectively came from the pool of its counterpart-Chinese Journal of Theoretical and Applied Mechanics. Translation of the paper was required to be done by authors themselves, and reviewed by experts in the field. Usually, an Associate Editor was assigned to evaluate the accuracy, conciseness of its language, followed by a last-round review by the Editor-In-Chief before sending out to the publisher.

From 1990, AMS started to accept manuscripts independently. AMS has a commission to promote creativeness and originality in mechanical research. It sets high quality of a paper as its rigorous standard, and the only one as well, for acceptance of articles for publication, which is broadly appreciated by researchers in the field. The famous mechanician W.J. Hutchinson praised that "papers in AMS are of high

\section{G.-D. Cheng ( $\square)$}

State Key Laboratory of Structural Analysis for Industrial Equipment, Department of Engineering Mechanics, Dalian University

of Technology, Dalian 116023, China

e-mail: chenggd@dlut.edu.cn quality, and comparable to those published in top journals in Applied Mechanics field."

With the rapid progress in science and technology in China, mechanical research in China enters a quick growth era. Submissions to AMS increase tremendously year by year. In 2002, AMS changed from quarterly to bimonthly publication, and the total number of pages per volume extended from 96 to 120 in 2004. The efficiency of publication was boosted by adopting internet in 2003; conventionally manual handling of manuscripts was replaced by online service, from submission, review, decision notification, proof, to publication. In recent years, the average period of paper publication in AMS is about 8 months. Meanwhile, members of CSTAM and subscribers can easily download papers from AMS website.

\section{Internationalization}

In 1991, the Editorial Board of AMS consisted of 35 internationally famous scholars in mechanics, which helped a lot for its internationalization and substantially promoted its worldwide impact in the field. Since 1991, AMS has been included by Engineering Index (EI), American Chemical Abstracts (CA), English Science Abstracts (SA), Japanese Current Bulletin on Science Technology (CBST) and Russian Abstract Journals (AJ). From 1995, AMS has been selected for Science Citation Index (SCI) database.

AMS continues its efforts to increase its international impact: more and more foreign experts are invited as Editorial Board members and reviewers; the famous publisher Springer was chosen as the journal's partner for its publication in 2005. Since then, download times of papers in AMS have been increased dramatically, and its scientific impact factor increased from 0.187 in year 1997 to 0.865 in 
year 2009! Before 2001, there were very few submissions from scholars out of China; the fraction of published papers by international scholars reached $26.2 \%$ in 2009 . It is selfevident that AMS has gained the attention and respect of more and more international mechanicians.

\section{Boosting career development}

From the very beginning, papers published in AMS stand for the top level progress for mechanics research in China. Lots of papers bear not only in-depth understanding and development in mechanics from academic aspects, but also bring in social and economical benefit. It is pleasant to see that many high impact papers in AMS come from the work of junior scientists. AMS has gradually become a forum for promising young mechanicians and helps to boost their career; many of them become rising star in their field from here.

\section{Continuous perfecting}

We are proud that Editors-in-Chief and the Editorial Board of AMS in the last 25 years are well known prestigious scholars in the field of mechanics. At the same time, the academic horizon of editors has been continuously improved as well. We commit to continue our tradition of publishing high quality and original work in the field to pay back our readers. Editors will treat each manuscript carefully, invite restrict yet knowledgeable referees, and push the limit of quick publication. We are confident that AMS will continue to be the homestead of worldwide mechanicians.

In the 25-year journey of excellence, AMS has become a flag-ship journal of mechanics and documented the achievement in mechanics by Chinese and world-wide mechanicians, as hoped by those founding Editorial Board members. Following the successful path of the journal and the steps of senior scientists in the field, we commit to continuously perfect it, and make the journal contribute more to the society of mechanics. 